\title{
CHARACTERISATION OF PARTIAL DISCHARGE PULSES IN ARTIFICIAL VOIDS IN POLYPROPYLENE FILMS USED IN CAPACITORS
}

\author{
B.Ramachandra R.S. Nema \\ Department of High Voltage Engineering \\ Indian Institute of Science \\ Bangalore 560012 \\ India
}

\begin{abstract}
Partial discharges in voids may cause deterioration of solid insulating materials. They often start in voids enclosed in insulation and or at the interface defects. A method of measuring fast discharge pulses with rise times below 1 ns is reported. Characterisation of partial discharge pulses in artificial voids in polypropylene films at atmospheric pressure is analysed that incorporates inception voltage, apparent and real charge, drift velocity and mobility of electrons.
\end{abstract}

\section{Introduction}

Polypropylene film is being widely used as dielectric in high voltage capacitors. One of the prime cause of insulation degradation is partial discharges in gas pockets or voids created between two adjacent films. Interpretation of physical processes in voids is complicated due to lack of knowledge of void shape, location and gas pressure. The purpose of present work is to investigate the mechanisms of discharges inside the void for various depths. To study pre-breakdown events in dielectrics, a time-dependent partial discharge model is presented. Ramo - Shockley theory is considered to study the relation between the motion of charges in an electrode gap and current induced in the external circuit. Very fast partial discharge current pulses in artificial voids in polypropylene are reported. The present model incorporates physics of partial discharge like drift velocity and mobility, real and apparent charge for different void depths. There are indication of streamer type of discharge in voids enclosed in solid insulation.

\section{Experimental Setup}

The experimental setup is shown in Figure 1. For high frequency response, subdivided electrode arrangement [1] was used. The radius of the measuring electrode should be small to reduce stray capacitances but not too small since otherwise the moving charge carriers also induce a current in the ground connection of the surrounding ring, thus reducing the current through the measuring resistor [2]. A $1 \mathrm{M} \Omega$ damping resistor close to the top electrode was provided for protection and to prevent reflections on high frequency currents on the high voltage lead. The diameter of subdivided electrode was $2 \mathrm{~cm}$ and $6 \mathrm{~cm}$ for measuring disk and guard electrode with $0.1 \mathrm{~cm}$ annular gap spacing between them. The upper electrode, encapsulated in epoxy, had a $2 \Pi / 3$ Rogowski profile and an effective uniform field diameter of $4.8 \mathrm{~cm}$.

The electrodes were made of high quality stainless steel and were cleaned with emery paper, benzene and acetone. The $50 \Omega$ measuring resistor consisting of six small 300 $\Omega$ metal film resistors connected in star configuration was placed below measuring electrode. The signal was fed by a $50 \Omega$ coaxial transmission line of one metre length to a $50 \Omega$ input of $1 \mathrm{GHz}$ Tektronix TDS 684A digital storage oscilloscope with a rise time of $350 \mathrm{ps}$. Recorded data on floppy was analysed by 386 PC.

Electrical grade bi-axially oriented $20 \mu \mathrm{m}$ thick and $11 \mathrm{~cm}$ diameter polypropylene films were used with an artificial cylindrical void of $0.2 \mathrm{~cm}$ diameter made at the centre as shown in Figure 2. The AC analogue circuit of Figure 2 is shown in Figure 3. Void depths of 80,120 and $200 \mu \mathrm{m}$ were studied. Additionally, samples without void for these thicknesses were also studied to check discharge free levels. Care was taken so that no air gap either between films or between film and electrode existed. The air pressure in the void was the local atmospheric pressure, 680 Torr.

The test voltage from a $50 \mathrm{kV}, 2 \mathrm{KVA}$ testing transformer was discharge free upto $22 \mathrm{kV}$. The pulse measurements described in this paper were performed at inception voltage. The TDS 684A oscilloscope was used in a single shot 
bandwidth of $1 \mathrm{GHz}$ with $5 \mathrm{G}$ samples/sec sampling rate.

\section{Experimental Results}

\subsection{Inception Voltage}

Figure 4 shows experimental and theoretical discharge inception voltages with varying void depth. Theoretical inception Voltage [3] is calculated by

$$
V_{\text {inc }}=\frac{E_{g}}{\epsilon_{r}}\left[t+t^{\prime}\left(\epsilon_{r}-1\right)\right]
$$

where $\mathrm{Eg}$ is the breakdown strength of the void and relative permitivity $\epsilon_{r}$ for $\mathrm{pp}$ is 2.2. Void inception Voltage is calculated by

$$
V_{v o i d}=\frac{V_{a p p}}{\left[1+\frac{\left(t-t^{\prime}\right)}{\epsilon_{r} t^{\prime}}\right]},
$$

where $V_{a p p}$ is the applied voltage across the sample. Figure 5 shows void inception voltage together with Paschen's value for different cavity depths.

\subsection{Apparent and Real charge}

The behavior of internal discharges in voids can be de scribed conveniently with the analogue circuit of dielectric and void as shown in Figure 3. In the analogue circuit, c represents the capacitance of the void, $b$ is the total capacitance in series with the void and $a$ is the remaining capacitance of the dielectric shunting the series combination of $b$ and $c$. The measurable charge is the apparent charge which is defined as the charge lost by the capacitor $c$ when discharge occurs in void and theoretical apparent charge is given by

$$
q_{a p p}^{t h e o}=\frac{\epsilon_{0} \epsilon_{r} A}{\left(t-t^{\prime}\right)}\left(V_{i n c}-V_{e x t}\right) .
$$

Theoretical real charge of the void is expressed by

$$
q_{\text {real }}^{\text {theo }}=q_{a p p}^{\text {theo }}\left[\frac{b+c}{b}\right]=q_{a p p}^{\text {theo }}\left[1+\frac{\left(t-t^{\prime}\right)}{\epsilon_{r} t^{\prime}}\right] .
$$

Figures 6 and 7 offer an illustration of the results obtained in Table $I$. The quoted experimental values are the average of ten measurements.

\subsection{Drift Velocity and Mobility}

Transit time of electrons can be determined theoretically from the drift velocity in air [4],

$$
v_{d}=1.334 X 10^{6}+4.222 X 10^{5}\left[\frac{E_{i n c}^{v o i d}}{p}\right],
$$

with $v_{d}$ in $\mathrm{cm} / \mathrm{sec}$ and $(\mathrm{E} / \mathrm{p})$ in $\mathrm{kV} / \mathrm{cm}$-bar. Extremely fast discharge pulses with rise time of the order of nanosecond and sub-nanosecond range have been recorded. Figure 8 shows the fastest discharge pulse recorded with a rise time of $454 \mathrm{ps}$ for $80 \mu \mathrm{m}$ void depth. The results of rise time are shown in Table I. From partial discharge pulse obtained, drift velocity of electrons is calculated by

$$
v_{d}^{c a l}=\frac{t^{\prime}}{t_{e}}
$$

Rise time of the pulse is considered for transit time of electrons $t_{e}$. Mobility of electrons is calculated by

$$
\mu_{e}=\frac{v_{e}^{c a l}}{E_{\text {inc }}^{\text {void }}} .
$$

Figures 9 and 10 offer an illustration of the results obtained in Table II.

\section{Discussion and Conclusion}

Theoretical analysis of the discharge current in voids shows that pulse rise times of few hundreds of ps are to be expected. In the literature measured rise times $[5,6]$ ranging from 400 to $800 \mathrm{ps}$ are reported. The present data shows correlation between recorded rise times and the void depth; discharge current rise times are faster for smaller void depths. The minimum rise time recorded in these studies was $454 \mathrm{ps}$ as shown in Figure 8.

This work shows that the apparent charge, at inception, calculated with the classical capacitance model is closer with measured values. The measured apparent charge has been calculated from the area of the pulse. It is seen that apparent discharge magnitude increases with void volume, from $50 \mathrm{pC}$ to $180 \mathrm{pC}$ for $80 \mu \mathrm{m}$ to $200 \mu \mathrm{m}$ void depth with $0.2 \mathrm{~cm}$ void diameter. The present data agrees with measured average discharge magnitude [7] by pulse distribution analysis. The theoretical estimation of apparent charge by Pedersen's model [6] shows decreasing trend with increasing void depth for our model. However for varying void depths with constant insulation thickness, Pedersen's model shows increasing trend of apparent charge with increase in void depth. Real charge of void has been estimated from the calculated and measured apparent charge.

This work reports extremely fast rise time pulses which requires several generation of electron production. The measured waveforms and drift velocity indicate streamer mechanism $[4,6]$ in the present work. Reported drift velocity is based on rise time of discharge pulse. The drift velocity of minimum rise time pulse is $2 \times 10^{5} \mathrm{~m} / \mathrm{sec}$ which is in reasonable agreement with values given [6] for streamer velocity. The electron mobility for $200 \mu \mathrm{m}$ void depth is $3.7 \times 10^{-2}\left(\mathrm{~m}^{2} /\right.$ volt-sec $)$ being close to the literature value [6] of $4 \times 10^{-2}\left(\mathrm{~m}^{2} /\right.$ volt -sec). 


\section{References}

1 H.F.A Verhart and P.C.T Van der lan. "Fast current measurements for avalanche studies ". J. Appl. Phys, Vol 53 (3), March 1982, PP 1430 - 1436.

2 M.G.Danikas. "Discharge studies in solid insulation in voids". IEEE Conf. on Electrical Insulation and Dielectric Phenomena, 1990, PP 249 - 254.

3 E.Hussain and R.S. Nema. " Analysis of Paschen curves for Air, N2 and SF6 using the Townsend breakdown equation ". Proc. IEEE Trans. on Electrical Insulation, Vol EI - 17, No 4, Aug 1982, PP 350 -353.

4 J.M.Wetzer et al ." Experimental study of the mechanism of partial discharges in voids in polyethylene ". 7 th Int. Symposium on High Voltage Engg, No 71.02, Aug 1991, PP $13-16$.

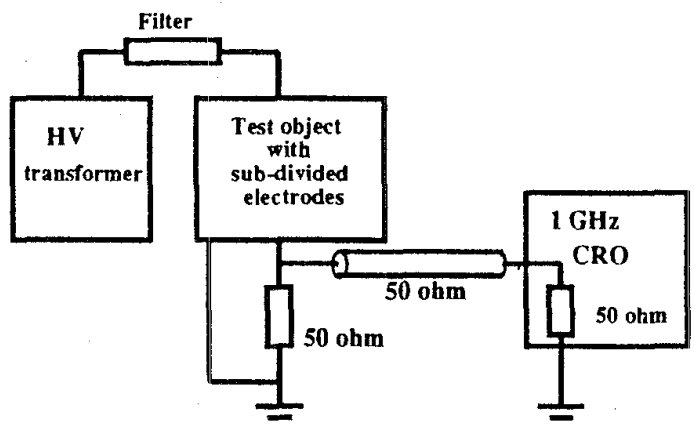

Figure 1 Experimental setup for pd measurements.
5 P.H.F Morshuis. " Time - Resolved discharge measurements ". Intl. Conf. on partial discharge, No 378, sept 1993 (IEE).

6 M.G.Danikas and A.M. Bruning. " Comparison of several theoretical sub-corona to corona transition relations with recent experimental results ". IEEE Intl. Symp. on Electrical Insulation, 1992, PP 383 - 388.

7 R. Shobha. "Internal partial discharge and breakdown characteristics of thin polypropylene films ". M.Sc Thesis, 1992, Dept of HVE, IISc, Bangalore.

Table 1

\begin{tabular}{|c|c|c|c|c|c|c|c|c|}
\hline \multirow{3}{*}{$\begin{array}{l}\text { Void } \\
\text { depth } \\
(\mathbf{m m})\end{array}$} & \multicolumn{3}{|c|}{$\begin{array}{l}\text { Apparent charge } \\
\text { (pC) }\end{array}$} & \multicolumn{3}{|c|}{$\begin{array}{l}\text { Real charge } \\
\text { (pC) }\end{array}$} & \multicolumn{2}{|c|}{$\begin{array}{c}\text { Measured Rise Time } \\
\text { (ns) }\end{array}$} \\
\hline & \multirow{2}{*}{ Theo } & \multicolumn{2}{|c|}{ Measured } & \multirow{2}{*}{ Theo } & \multicolumn{2}{|c|}{ Measured } & \multirow{2}{*}{ + ve pulse } & \multirow{2}{*}{-ve pulse } \\
\hline & & +ve pulse & -ve pulse & & + ve pulse & -ve pulse & & \\
\hline 0.08 & 81.6 & 53.2 & 52.9 & 100.1 & 65.3 & 64.9 & 0.754 & 0.8 \\
\hline 0.12 & 141.4 & 117.5 & 108.8 & 162.8 & 135.3 & 125.3 & 0.991 & 0.98 \\
\hline 0.20 & 180.0 & 165.5 & 176.7 & 196.4 & 180.6 & 192.8 & 1.43 & $1.4 \|$ \\
\hline
\end{tabular}

Table II

\begin{tabular}{|l|c|c|c|c|}
\hline \multirow{2}{*}{$\begin{array}{c}\text { Void } \\
\text { depth } \\
(\mathrm{mm})\end{array}$} & $\begin{array}{c}\text { Measured Drift Velocity } \\
\times 10^{5}(\mathrm{~m} / \mathrm{sec})\end{array}$ & \multicolumn{2}{|c|}{$\begin{array}{c}\text { Measured Mobility } \\
\left(\mathrm{m}^{2} / \text { Volt-sec }\right)\end{array}$} \\
\cline { 2 - 5 } & + ve pulse & -ve pulse & +ve pulse & -ve pulse \\
\hline 0.08 & 1.06 & 1.00 & 1.62 & 1.53 \\
0.12 & 1.21 & 1.22 & 2.32 & 2.35 \\
0.20 & 1.39 & 1.42 & 3.64 & 3.71 \\
\hline
\end{tabular}




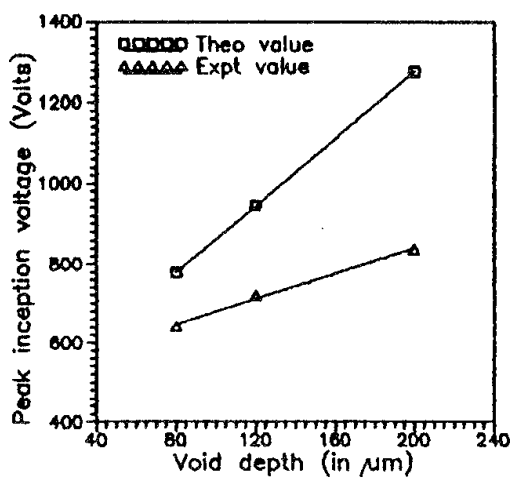

Fig. 4 Variation of inception voltoge with void depth.

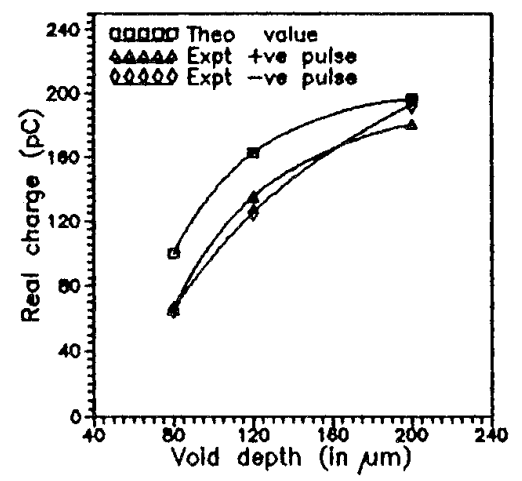

Flg.7 Voriotion of real charge with void depth.

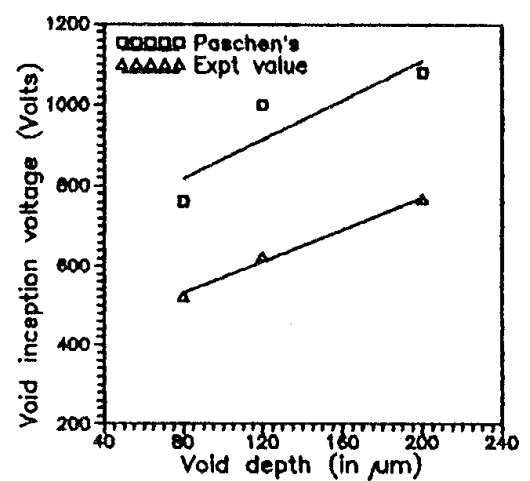

Fig.5 Voriation of void inception voltoge (peak) with void depth.

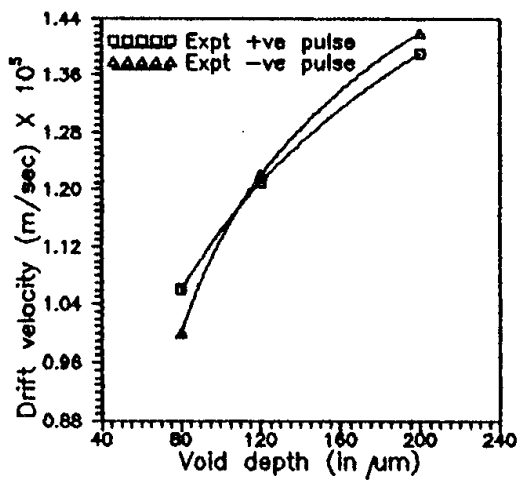

Fig.8 Vorlation of drift velocity with void depth.

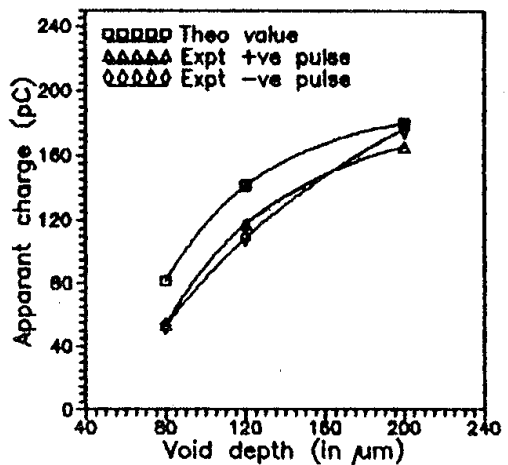

Fig.6 Varlation of apporent charge with void depth.

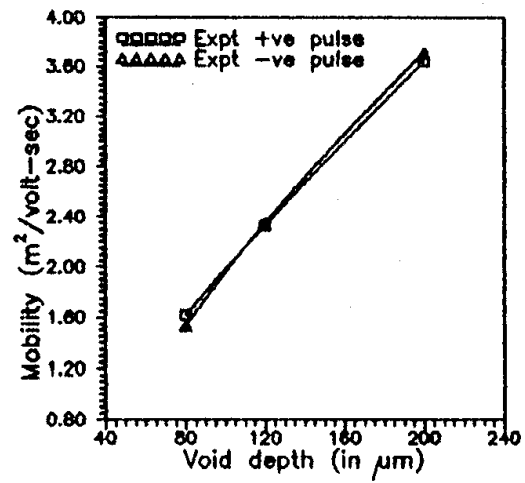

Fig.10 Voriation of mobillty with void depth.

Tek blab. single seq 5.00Gs/s

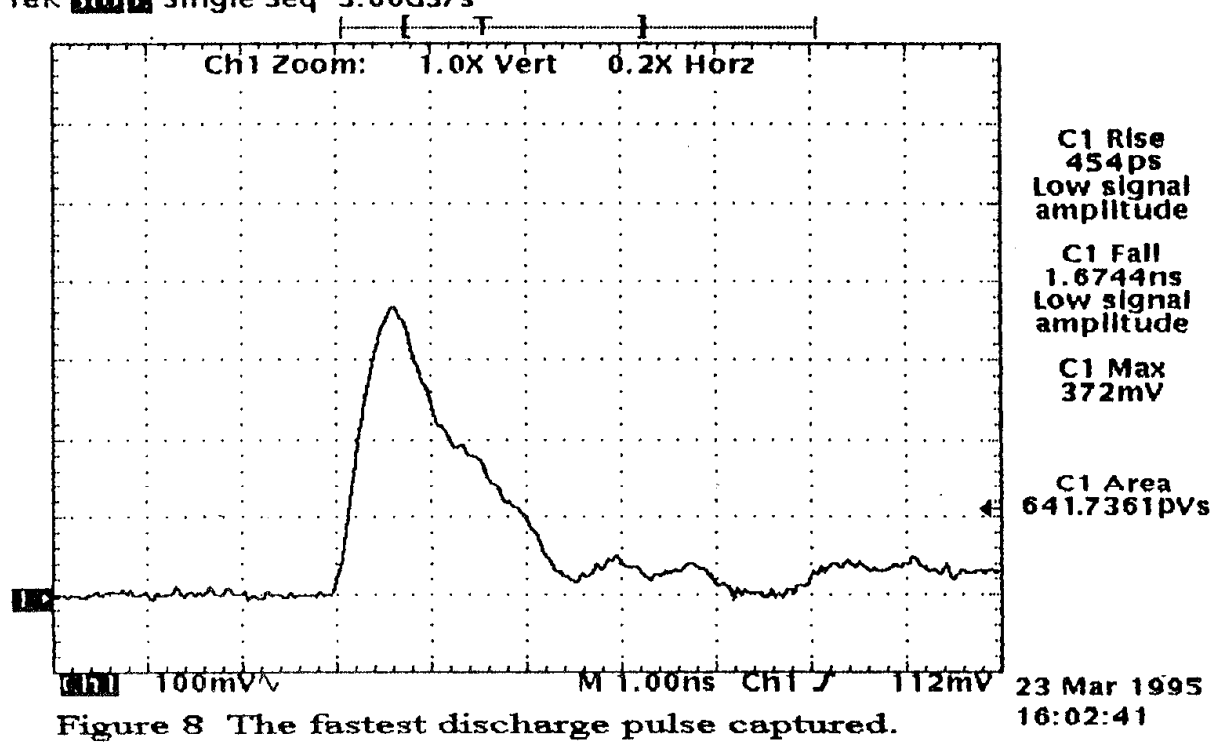

